NASA CONTRACTOR REPOR T

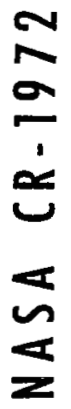

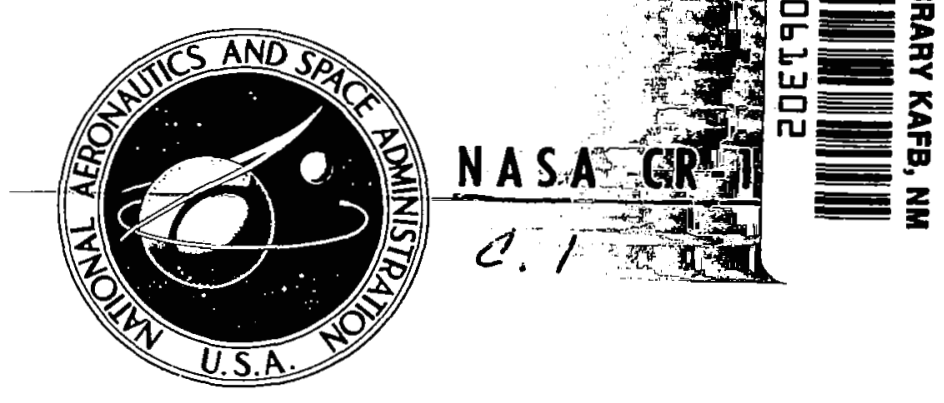

LOAN COPY: RETURN TO AFWL (DOUL) KIRTLAND AFB, N. M.

\title{
PHYSICAL PROPERTIES \\ OF THIN FILMS
}

by P. R. Preiswerk and M. E. Lippman

Prepared by

ASTRO RESEARCH CORPORATION

Santa Barbara, Calif. 93103

for

NATIONAL aERONAUTICS AND SPACE ADMINISTRATION - WASH!NGTON, D. C. FEBRUARY 1972 
1. Report No.

NASA CR-1972

4. Title and Subtitle

PHYSICAL PROPERTIES OF THIN FILMS
2. Government Accession No.

3. Recipient's Catalog No.

5. Report Date

February 1972

6. Performing Organization Code

8. Performing Organization Report No. $A R C-R-48]$

10. Work Unit No.

9. Performing Organization Name and Address

Astro Research Corporation

Santa Barbara, California 93103

12. Sponsoring Agency Name and Address

National Aeronautics and Space Administration Washington, D.C. 20546

15. Supplementary Notes
11. Contract or Grant No.

NAS7 -728

13. Type of Report and Period Covered Contractor

Final Report

14. Sponsoring Agency Code

RWS

16. Abstract

Studies and experiments on vapor deposited carbon, boron, aluminum oxide, zirconium silicate, aluminum, and titanium on polyimide film substrates.

17. Key Words (Suggested by Author(s))

Thin films, vapor deposition, composite laminates
18. Distribution Statement

Unlimited

1. Thin

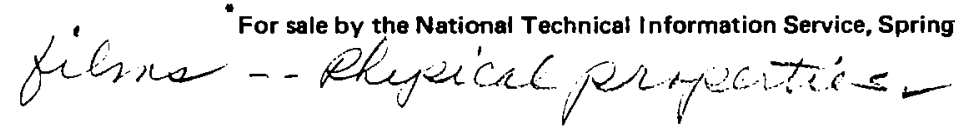

20. Security Classif. (of this page)

Unclassified
21. No. of Pages 32
22. Price* $\$ 3.00$ 



\section{SUMMARY}

A study was conducted to investigate the physical properties of thin film composites. Electron beam physical vapor deposition techniques were employed to prepare composite specimens of vitreous carbon, boron, aluminum oxide, zirconium silicate, aluminum, and titanium on Kapton* $H$ film polyimide substrates.

Specimens of the composites in strip form were subjected to stress-strain and ultimate strength tests. The thermal expansion was determined optically by comparison to a standard of known thermal expansion. Density was determined for carbon films by independent measurements of film thickness and mass.

For metal films the results indicate that the modulus of elasticity is independent of the deposited film thickness. The ultimate strength of metal films increases as their thickness decreases.

For carbon films, all physical properties measured are affected by film thickness. Thinner films show higher strength, modulus, and density. Thermal expansion between 20 and $100^{\circ} \mathrm{C}$ of vitreous carbon films was close to zero with a definite negative trend for thinner films. A composite specimen using alternating very thin layers of carbon and titanium was prepared, and its mechanical properties were determined. The measurements indicate that the unusually high elastic properties of thin carbon films can be retained by this method in relatively thick composite depositions.

*Kapton, E.I. DuPont 


\section{CONTENTS}

\section{Page}

1. INTRODUCTION 1

2. PREPARATION OF THIN FIIM COMPOSITES

3. DENSITY DETERMINATION - DIRECT AND INDIRECT METHODS 4

4. MECHANICAL PROPERTIES 6

4.1 Test Setup 6

4.1.1 Calibration 6

4.1.2 Specimen preparation 6

4.2 Test Procedures 7

4.2.1 Stress-strain tests 7

4.2.2 Ultimate stress and elongation 7

4.3 Evaluation 8

4.3.1 Elastic properties of substrates 8

4.3.2 Elastic modulus of deposited films 8

4.3.3 Ultimate stress 9

5. THERMAL EXPANSION 10

5.1 Test setup 10

5.2 Calibration 10

5.3 Test Procedure 11

5.4 Evaluation 11

6. CONCLUSIONS 13

$\begin{array}{ll}\text { REFERENCES } & 15\end{array}$ 
1. INTRODUCTION

The favorable mechanical-physical properties of structural materials in the form of very thin elements is well known and widely employed in the technology of fiber composite materials.

Similarly advantageous properties have been found in thin films (Ref. 1). The origin of such anomalous behavior is not well established. It is apparent, however, that very thin films, made for instance by direct condensation from the vapor phase, exhibit crystallographic properties which are markedly different from materials formed by more conventional processes. Metallic deposited films show extremely fine crystallite structures and large dislocation densities which are otherwise only achieveable by extreme cold-working. Deposited films made from carbon and from ceramic materials show frequently a total absence of recognizable crystal structures, anomalous density, low thermal expansion, and strongly thickness-dependent elastic and strength properties.

If such properties can be imparted to structural components made from deposited films by lamination techniques, mechanical advantages over fiber composites can be expected. These advantages have been explored in previous studies (Refs. 2, 3) and are basically associated with two factors:

The use of a film reinforced composite provides inherently two-dimensional strength and stiffness characteristics without recourse to cross-lamination which is required in fiber composites. This allows potentially efficient application of composite film technology in many structural applications beyond those for which filamentary composites are clearly indicated.

Secondly, because of the bidirectional property of film reinforcements, the requirements for a structurally strong "matrix" material is relaxed and its function is principally reduced to one of interlaminar adhesion. Therefore, low density, lightweight matrix materials can be employed which permit the production of low density composites. Low density composites are desirable, particularly for the design and fabrication of lightly loaded structural panels which comprise a large fraction of aeronautical and spacecraft structures. 
The purpose of the present program was to determine mechanical and physical properties of the vacuum deposited film materials, to compare these data with established bulk values and to examine possible correlation between the thickness of the deposited film and its properties.

Properties determined include density, the modulus of elasticity in tension, the ultimate tensile strength, ultimate elongation and the coefficient of thermal expansion (CTE) between $20^{\circ}$ and $100^{\circ} \mathrm{C}$.

Primary materials investigated were aluminum, titanium, and carbon. Single sample tests were performed with boron, aluminum oxide, zirconium silicate, and a titanium/carbon alternating layer composite. 


\section{PREPARATION OF THIN FIIM COMPOSITES}

A variety of composites were prepared using an electron beam physical vapor deposition system. Thin films of carbon, boron, aluminum oxide, zirconium silicate, aluminum, titanium, and titanium-carbon were deposited on both sides of thin polyimide sheet substrates.

The substrates, approximately $4 \times 6^{\prime \prime}$ in area and $1 / 2 \mathrm{mil}$ or $1 / 4$ mil thick, were supported in a metal frame which provided a nominal longitudinal tension of 5 lb to keep the substrates taut. The frame was rotated at $60 \mathrm{rpm}$ during deposition, thereby providing equal film thickness on both substrate surfaces.

The substrate films were cleaned by using an ultrasonicdetergent bath with subsequent acetone and isopropyl alcohol wash and de-ionized water rinse. After closing the chamber, substrates were heated to $150-200^{\circ} \mathrm{C}$ for approximately one hour, at a background pressure of $2 \times 10^{-5}$ torr. Evaporation of the source material was accomplished by electron beam heating to an appropriate temperature. Typical beam current was controlled at approximately 150-200 milliamperes. Deposition rates and final thickness of the film was monitored and controlled using quartz crystal sensors and associated control circuitry.

Composite films consisting of alternating layers of titanium and carbon were produced by using a double hearth provision of the electron beam vacuum deposition equipment. At pre-set intervals the beam was switched to deposit either carbon or titanium from the two hearths, thus producing the desired layered deposit. 


\section{DENSITY DETERMINATION - DIRECT AND INDIRECT METHODS}

The mass gain per unit surface area attributed to the deposited thin film was measured for all test specimens using an Ainsworth precision microbalance having a sensitivity of 0.01 milligrams.

The density of deposited films was determined from their mass and thickness, as measured. The thickness of the relatively thick films was determined with precision micrometers by measuring substrate thickness prior to deposition and total thickness after deposition.

In the case of thinner films, micrometer measurements were inadequate, and consequent $l_{y}$ measurement was made with an optical interferometer augmented with a filar eyepiece. In most cases these measurements were made of films deposited on test glass flats which were located adjacent to the test specimens during deposition. In order to optimize the measurement the test glass was overcoated with silver - a conventional procedure. The range of accuracies was $\pm 1 \%$ at 10 fringes, $\pm 5 \%$ at 3 fringes, $\pm 50 \%$ at $1 / 10$ fringe. The instrument employed a sodium light source with a wavelength of $5890 \AA$, and a fringe of $2945 \AA$.

A secondary method of mass determination made use of the quartz microbalance which is a portion of the deposition control sensor system of the deposition equipment. The procedure depends on the ability of the quartz crystal oscillator to detect the mass of a material which is deposited on it. Two special precautions were observed. The crystal was mounted quite far from the source $(30 \mathrm{~cm})$ to minimize thermal effects, and a $50 \%$ transmission mask (confirmed to 49.5 to 50.5\%) was used to minimize the stress effects observed on carbon deposits. During deposition, flats were again located adjacent to the crystals at the same distance from the source. Thickness of the film on the flats was measured using multiple beam interferometry. Typical measurements on carbon films were as follows:

$\begin{array}{ccc}\text { Thıckness }(\AA) & \text { Crystal Excursion } & \frac{\text { Density } \mathrm{g} / \mathrm{cm}^{3}}{2.5} \\ 650 & .42 \mathrm{KHz} & 2.5 \\ 2230 & 1.40 \mathrm{KHz} & 2.5 \\ 4900 & 3.0 \mathrm{KHz} & 2.3\end{array}$


In order to calibrate the crystal, a final deposition was made with aluminum. It is generally reported in the literature that the density of a $1 / 2$ micron aluminum film deposited at a rate of over $15 \AA / \mathrm{sec}$ and a pressure of $5 \times 10^{-5}$ torr, approaches bulk density. These conditions were observed in the deposition calibration. The crystal constant was found to be approximately 1.93 which compares to the manufacturers rating of 2.00 , a difference of $3.5 \%$.

Results obtained by the two methods from various carbon films are summarized in Figure 1. The density of relatively thick films is approximately equal to the reported bulk density of vitreous carbon (Ref. 4) but significantly larger for thinner films, approaching that of diamond (Ref. 5). 


\section{MECHANICAI PROPERTIES}

\subsection{Test Setup.}

The basic setup for stress-strain and strength tests is shown in Figure 2. Test specimens were suspended from the horizontal rod of a small portal frame and loaded with calibrated deadweights. The elongation of the test specimen was measured between two paint markings by a twin Gaertner microscope with filar eyepieces. In the case of the ultimate strength tests of conductive films the electric resistance of both coated sides was monitored in order to detect the first crack in the deposited film.

4.1.1 Calibration. The two Gaertner telemicroscopes were mounted in horizontal position in a stand which allows vertical adjustment for both microscopes individually. The top telemicroscope with an $f 80 \mathrm{~mm}$ lens and a 12.5 power filar eyepiece (800 divisions) was calibrated at $140 \times 10^{-6}$ inch/division; the bottom telemicroscope with an $f 38 \mathrm{~mm}$ lens and a 10 power filar eyepiece (800 divisions) was calibrated at $45 \times 10^{-6}$ inch/divisions. Gauge blocks and a precision steel ruler were used as calibration references. Both eyepieces were turned $45^{\circ}$ in order to get one crosshair into a horizontal position. This way the markings on the test specimens could be sighted better and the sensitivity of measurement was increased by a factor of $\sqrt{2}$. Small lead weights were calibrated on an Ohaus triple beam balance to within $\pm 0.1 \mathrm{~g}$ of nominal values of 25,50 , and $100 \mathrm{~g}$. In addition a weight hanger of $75 \pm 0.1 \mathrm{~g}$ was fabricated. This hanger served as a preload in the tests and provided the necessary suspension points for the load increments.

4.1.2 Specimen preparation. Strips of 0.25 in. width were cut from each $4 \times 5$ in. deposition sample. One end was glued with Eastman 910 adhesive to a small rectangular aluminum plate which then was attached to the crossbar of the portal frame. A small aluminum shim with a hole in the center was glued to the free end of the specimen. Each specimen received paint markings at the edge, one close to the suspension plate, the other about half an inch above the loading point. The distance between the two markings was measured with a cathetometer of \pm 0.001 in. accuracy. The same instrument was used to determine the width of the specimen at various places. 


\subsection{Test Procedures.}

4.2.1 Stress-strain tests. The specimen was suspended from the portal. frame and the heights of the microscopes were adjusted. The coated specimens were preloaded by attaching the weight hanger. Load increments of $25 \mathrm{~g}$ were applied in twominute intervals. When the elongation reached or exceeded $0.2 \%$ the process was reversed and $25 \mathrm{~g}$ weights were removed, one every two minutes. The cycle of loading and unloading was repeated at least once for each sample. Elongations were measured by taking two readings with the bottom microscope, one on the specimen marking and one of a marking placed on an unstressed metal strip hanging beside the test specimen. This metal strip (molybdenum shim 0.25 in. $x 0.010$ in. $x 6$ in.) was attached to the same aluminum plate the test specimen was suspended from. Thus, the lower edge of this plate could be used as the reference marking on both test specimen and metal strip. Readings made with the upper microscope confirmed that there was no measurable deflection of the suspension plate or slippage of the test sample.

\subsubsection{Ultimate stress and elongation. Electrically} conductive films were prepared as for the stress-strain test but were, in addition, wired to monitor the electric resistance of the coating. At the upper end of the specimen a loop of No. 36 wire was attached to both film sides with a DuPont silver preparation (electronic grade 4817). This wire was insulated against surrounding metal structures by electric masking tape. At the lower specimen end just above the loading point, two additional wires were affixed with the same silver preparation. Care was taken that each wire was fastened to opposite sides of the specimen and that any shorting contact between the two sides, by the wires or the silver adhesive, was avoided. The wires were connected to a portable simpson volt and ohm meter. Load increments were applied at two-minute intervals. Strain and resistance were measured at each load increment of $50 \mathrm{~g}$. The test was terminated either when the specimen ruptured or when the resistance showed a sudden substantial increase. In this case one of the lead wires was disconnected from the specimen and in its place a probe was inserted in the ohm meter. By moving the probe along the film surface it was possible in some instances to locate the failure area. 


\subsection{Evaluation.}

4.3.1 Elastic properties of substrates. A series of stress-strain tests on typical uncoated specimens was conducted. Specimens included $1 / 2 \mathrm{mil}$ and $1 / 4 \mathrm{mil}$ nominal thickness material as received, material which has been heat treated, and material from the uncoated margins of deposition samples. Results of these tests are summarized in Table I.

The modulus of elasticity was established as the tangent modulus at $0.2 \%$ elongation.

In the process of extracting properties of the film materials from the test results of the composites, data of an appropriate substrate test was used; $i . e .$. in the case of preheat treated Kapton the respective substrate data was readily available while for all other samples one of the heat-exposed margin specimens was chosen as reference.

4.3.2 Elastic modulus of deposited films. The modulus of elasticity of the vacuum-deposited film $E_{f}$, was determined by the rule of mixture as:

$$
E_{f}=\left(E_{c}-E_{s} \frac{t_{s}}{t_{c}}\right) \frac{t_{c}}{t_{f}}
$$

where $t_{C}$ is the total thickness of the specimen, $t_{f}$ the total thickness (both sides) of the deposition, $t_{S}$ the thickness of the substrate, $E_{S}$ is the appropriate tangent modulus of the substrate, and $E_{C}$ the tangent modulus of the composite at $0.2 \%$ elongation determined as an average from four load-deflection cycles.

Values of $E_{f}$ and $E_{C}$ are listed in Tables II to $V$.

Figure 3 shows the elastic modulus of the aluminum and titanium films in function of total (both sides) deposited film thickness, and a comparison to accepted values for these metals in bulk form. 
Figure 4 shows similar data for carbon films and a comparison to published data for vitreous carbon (Ref. 6) and diamond (Ref. 5). Because of the wide spread of data they are represented on a log-log plot.

4.3.3 Ultimate stress. The ultimate stress of thin films was calculated from the static equilibrium condition

$$
\sigma_{c} t_{c}=\sigma_{f} t_{f}+\sigma_{s(\varepsilon)} t_{s}
$$

The stress in the Kapton substrate, $\sigma_{\mathbf{S}}(\epsilon)$, is found for the measured elongation at failure, $\varepsilon$, in the appropriate stressstrain plots from uncoated specimen tests.

Data for elastic modulus, elongation at failure, and stress at failure are tabulated for aluminum films in Table II, for titanium films in Table III, for carbon films in Table IVa and $I V b$, and in Table $V$ for various films made from boron, zirconium silicate (zircon), aluminum oxide, and for titanium/carbon layered composite films.

Figure 5 shows the ultimate tensile stress in function of deposited film thickness (both sides) of metal films. Figure 6 shows similar data for carbon films. In both cases a significant increase in strength is evident, as the film thickness is decreased. 


\section{THERMAI EXPANSION}

\subsection{Test setup.}

The specimens were glued with Eastman 910 adhesive at their top end to a small aluminum plate, then hung side by side to a calibrated molybdenum standard. At the lower end of the specimen a target made from a piece of copper shim was attached.

The specimen and the molybdenum standard were carefully arranged such that the lower rim of the molybdenum standard and the top of the copper shim hung at the same level and in the same plane. This unit then was attached to a stand inside a temperature controlled test chamber equipped with a high quality window for optical length measurement. The length of the specimen from the top to the copper shim and the length of the standard were measured with a cathetometer. To keep the speciment straight a small weight of $7.1 \mathrm{~g}$ was attached to the copper shim, and a paper clip clamped over the standard prevented the specimen from swinging out of plane and focus.

The difference of elevation between the lower edge of the standard and the top of the copper shim was measured with a Gaertner telemicroscope (f $38 \mathrm{~mm}$ lens) and a cooke image splitting eyepiece. The microscope had been calibrated by the same method used in the stress-strain tests. One division of the eyepiece screw corresponds to $81 \times 10^{-6} \mathrm{in}$. The telemicroscope was mounted horizontally in a stand just in front of the observation window and could be adjusted in all three directions.

The test chamber was heated by a'500 watt heating element. care was taken to prevent direct radiation to the specimen and the thermometers. In addition, baffles were used to reduce thermal gradients. The temperature was measured directly with mercury thermometers visible through the window. The cooling of the chamber was accelerated by running water through its hollow walls.

\subsection{Calibration.}

A primary vitreous silica standard rod of 0.25 in. diameter had been obtained from the National Bureau of Standards. Its thermal expansion $\epsilon_{\tau}$ (in parts per million) is reported by NBS to be described by the following polynomial: 


$$
\begin{aligned}
\epsilon_{T}=117.32 & -215.73\left(\frac{T}{100}\right)+103.67\left(\frac{T}{100}\right)^{2}-20.270\left(\frac{T}{100}\right)^{3} \\
& +2.0991\left(\frac{T}{100}\right)^{4}-0.093006\left(\frac{T}{100}\right)^{5}
\end{aligned}
$$

A thin molybdenum strip 0.010 in. thick and 0.250 wide was calibrated against the silica standard by the same method used to determine the CTE of the test samples. The results of this calibration yielded a thermal expansion coefficient

$$
a_{\mathrm{mo}}=(4.15 \pm 0.29) \times 10^{-6} /{ }^{\circ} \mathrm{C}
$$

This molybdenum strip was used subsequently in all thermal expansion tests as a secondary standard.

\subsection{Test Procedure.}

After placing the specimen and the standard in the environmental chamber the temperature was cycled at least twice from room temperature to $120^{\circ} \mathrm{C}$ at a rate of approximately $\pm 1 \%$ minute. Readings were taken at intervals of 10 degrees.

\subsection{Evaluation.}

The coefficient of thermal expansion (CTE) of each specimen was determined from the measurements for the temperature interval from $20^{\circ} \mathrm{C}$ (room temperature) to $100^{\circ} \mathrm{C}$.

The difference between the two image splitter readings was interpreted in terms of the changing distance between the edges of the molybdenum standard and the copper shim on the specimen in function of temperature. With the length of the specimen, and the length and CTE of the standard known the coefficient of thermal expansion of the composite could be determined from the measured differential in elongation due to temperature.

The CTE of the deposited film material, $\alpha_{f}$, was calculated according to the "rule of mixture" 


$$
\alpha_{E}=\alpha_{c}-\left(\alpha_{s}-\alpha_{c}\right) \frac{t_{s} E_{s}}{t_{f} E_{f}}
$$

Data for $\sigma_{f}$ and $\alpha_{C}$ are tabulated for the various materials in Tables $I^{f}$ through $V$. Figure 7 shows the CTE for aluminum, titanium, and carbon films in function of deposition thickness. Values for zircon, boron, and aluminum oxide obtained from single sample tests are also shown. 


\section{CONCLUSIONS}

The results from this experimental program are generally of a preliminary nature. Measured physical properties show considerable scatter. This is in part due to experimental difficulties in measuring the properties of very thin films, partly due to process variables encountered in the preparation of certain types of thin film composites. Based upon available evidence so far, the following conclusions can be stated.

Deposited films of significant structural stiffness and strength can be made from a wide range of materials by physical vapor deposition techniques.

Layered composites from alternating ultra-thin deposits of titanium and carbon can be made by the same techniques.

All films studied in this program can be made with smooth surface appearance such that physical properties of laminates made with such films can be expected to retain the basic film properties without significant degrading due to imperfection. Such deficiencies have been observed in other development programs using boron depositions on kapton substrates where only a fraction of the expected physical properties could be realized in the composite.

The tensile strength of aluminum and titanium films and their elastic range of elongation is significantly higher than published values for bulk forms of the same material. Measured tensile stress at failure increases as film thickness decreases. Maximum tensile strengths of approximately 300,000 psi have been observed in films made from either material (Fig. 5).

The density, elastic modulus, and tensile strength of carbon films increases dramatically as film thickness is reduced. Carbon films with moduli of 50 to $130 \times 10^{6} \mathrm{psi}$ and ultimate tensile strengths of 400,000 psi have been observed (Figs. 4, 6). High moduli and tensile strength are retained in multiple layer deposits, provided that the individual carbon layers remain separated by an intervening layer of titanium.

Abnormal thermal expansion coefficients are observed in carbon and aluminum oxide films. A single aluminum oxide film sample tested showed a strongly negative expansion coefficient 
of $-7.1 \times 10^{-6} /{ }^{\circ} \mathrm{C}$. Carbon films show very small (close to zero) expansion coefficients for moderate film thickness with a tendency to negative values for very thin films (Fig. 7).

The data obtained so far suggest that the abnormal properties of thin films might be associated with a "surface skin" effect, similar to that which has been postulated by shanley et al (Ref. 6, 7) as an explanation for the abnormally high strength and increased elastic moduli observed in thin fibers.

Further investigations, particularly involving a definition of the crystallographic structure in deposited thin films is required to elucidate and confirm the observed effects. Application studies may be initiated with the purpose of making the extra-ordinary properties of deposited film composites available to the structural designer for application to advanced high performance airframe and spacecraft components. Such an advanced concept, using in-space fabrication of thin films, has been investigated in a previous study and discussed in Reference 8. Another potential use exploits the low expansion coefficients of carbon and possibly aluminum oxide films for the design of extremely stable structures required, for instance, in microwave filters and in optical instruments subject to temperature variations. 


\section{REFERENCES}

1. Beams, T.W.: "Mechanical. Strength of Thin Films of Metals", Phys. Rev. 100, p. 1657-1661 (1955).

2. Crawford, R.: "An Evaluation of Boron Polymer Film Layer Composites for High Performance structures", NASA CR-1114, September 1968 .

3. Crawford, R.: "Efficiency of Boron-Carbon-Polymer Laminated Film Composites for Stability Designed structures", paper 71-353, AIAA/ASME 12th Structures, Mechanics Conference. April 19-21, 1971 .

4. Crawford, F.C., Lewis, J.C.: "Vitreous Carbon - A New Form of Carbon", J. of Materials Science, 2, 507-512 (1967).

5. Huntington, H.B.: "The Elastic constants of Crystals", Academic Press, Inc., 1958.

6. Shanley, F.R.: "On The Strength of Fine wires", Rand Corporation, paper No. P-1654 (April 1959).

7. Schuerch, H.: "Effect of Diameter Upon Elastic Properties in Thin Fibers", J. AIAA, Vol. 2, 569-571 (March 1964).

8. Lippman, M.: "In space Fabrication of Thin Film structures", Astro Research Corporation, Report ARC-R-410, October 1970. 
TABLE I. MECHANICAI AND PHYSICAL PROPERTIES OF KAPTON SUBSTRATE

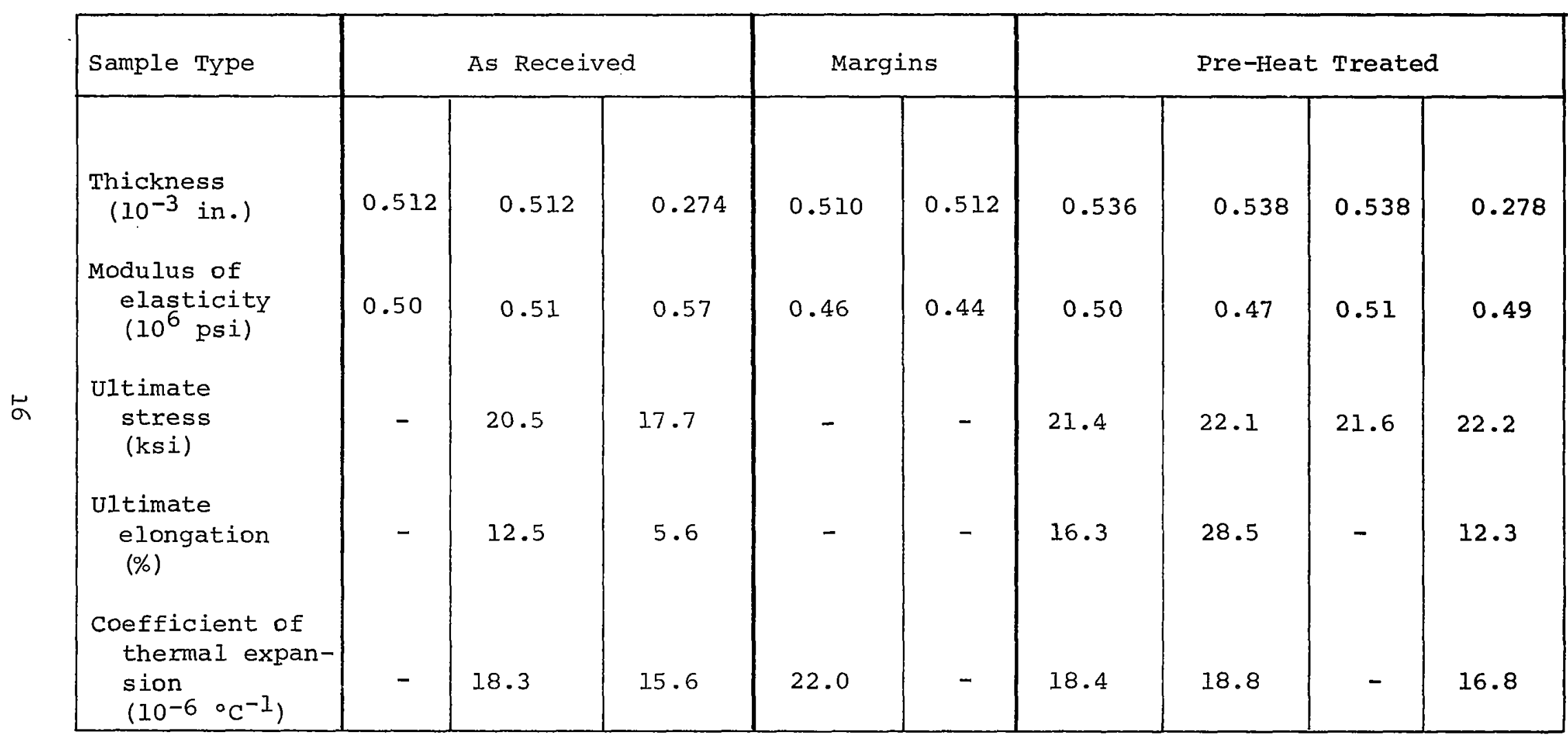


TABLE II. MECHANICAI AND PHYSICAI PROPERTIES OF ALUMINUM/KAPTON FILMS

\begin{tabular}{|c|c|c|c|c|c|c|c|c|c|c|}
\hline $\begin{array}{l}\text { Specimen } \\
\text { Identification }\end{array}$ & $\begin{array}{c}105- \\
55- \\
1\end{array}$ & $\begin{array}{c}105- \\
55- \\
2\end{array}$ & $\begin{array}{c}105- \\
44,46 \\
2\end{array}$ & $\begin{array}{c}105- \\
44,46 \\
4\end{array}$ & $\begin{array}{c}105- \\
46,47 \\
2\end{array}$ & $\begin{array}{c}105- \\
46,47 \\
4\end{array}$ & $\begin{array}{c}105- \\
52- \\
1\end{array}$ & $\begin{array}{c}105- \\
52- \\
4\end{array}$ & $\begin{array}{c}114- \\
1- \\
3\end{array}$ & $\begin{array}{c}114- \\
1- \\
4\end{array}$ \\
\hline $\begin{array}{l}\text { Thickness (10 }{ }^{-3} \text { in.) } \\
\text { Specimen, total } \\
\text { Kapton substrate } \\
\text { Aluminum coating, } \\
\text { total } \\
\text { Modulus of elasticity } \\
\text { (106 psi) } \\
\text { Composite } \\
\text { Kapton substrate } \\
\text { Aluminum coating } \\
\text { Ultimate elongation } \\
\text { of aluminum } \\
\text { coating (\%) } \\
\text { Stress of coating } \\
\text { failuxe (ksi) } \\
\text { Composite } \\
\text { Aluminum coating } \\
\text { Coefficient of ther- } \\
\text { mal expansion } \\
\text { (10-6 a }{ }^{-1} \text { ) } \\
\text { Composite } \\
\text { Kapton substrate } \\
\text { Aluminum coating }\end{array}$ & $\begin{array}{l}0.75 \\
0.435 \\
10.26 \\
1.81 \\
13.9 \\
247.5\end{array}$ & $\begin{array}{l}0.87 \\
0.435 \\
14.0 \\
1.72\end{array}$ & $\begin{array}{l}0.548 \\
0.512 \\
0.036\end{array}$ & $\begin{array}{l}1.00 \\
0.435 \\
9.04 \\
1.07\end{array}$ & $\begin{array}{l}0.618 \\
0.512 \\
0.106\end{array}$ & $\begin{array}{l}0.618 \\
0.512 \\
0.106\end{array}$ & $\begin{array}{l}1.94 \\
0.435 \\
9.21 \\
1.04\end{array}$ & $\begin{array}{l}\ddots \\
24.2 \\
19.2 \\
25.0\end{array}$ & $\begin{array}{l}0.638 \\
0.512 \\
0.126\end{array}$ & $\begin{array}{l}2.42 \\
0.435 \\
10.24\end{array}$ \\
\hline
\end{tabular}


TABLE III. MECHANICAL AND PHYSICAL PROPERTIES OF TITANIUM/KAPTON FILMS

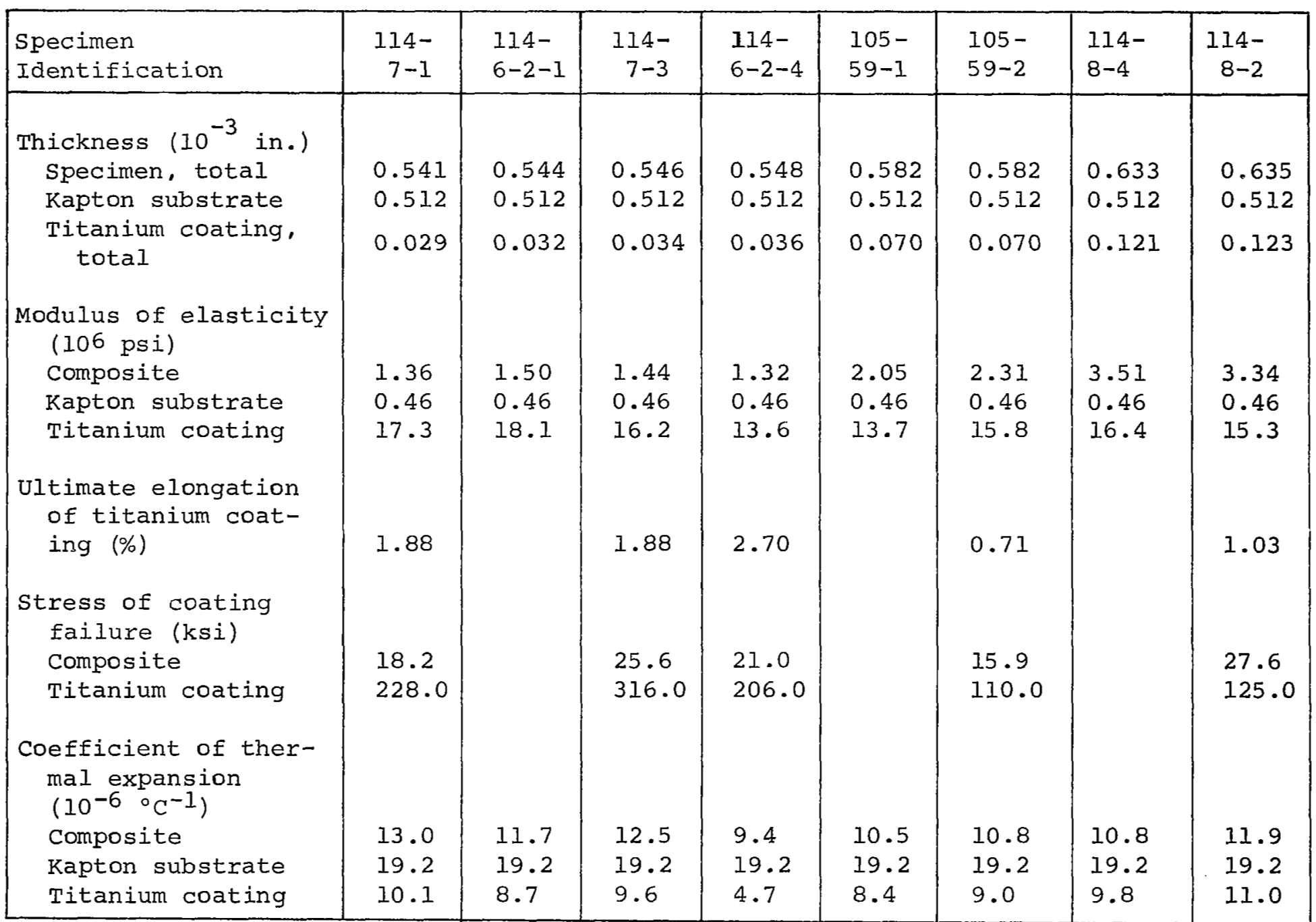


TABLE IV(a). MECHANICAL AND PHYSICAL PROPERTIES OF CARBON/KAPTON FILMS

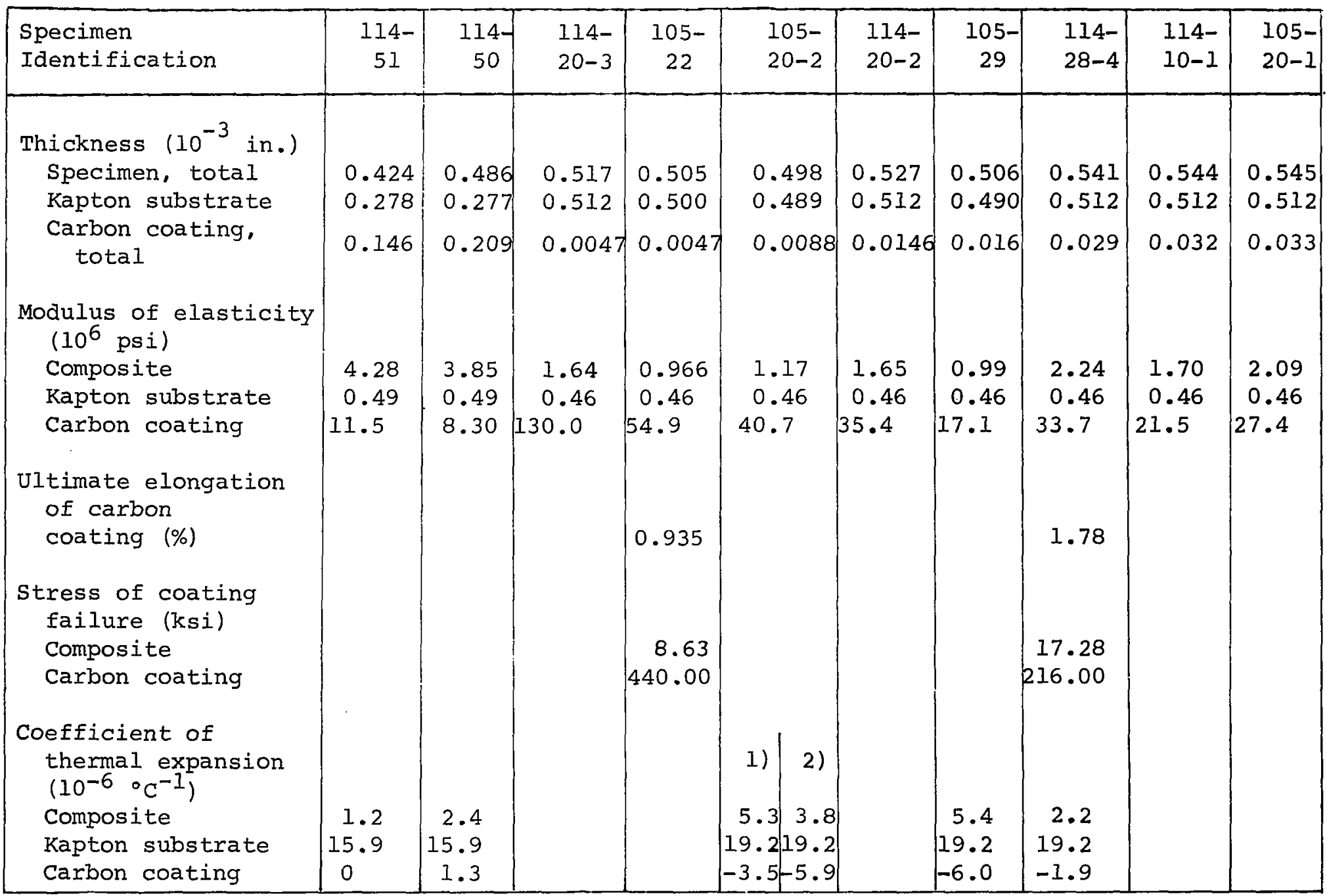

1) For increasing temperature 20 to $100^{\circ} \mathrm{C}$

2) For decreasing temperature 100 to $20^{\circ} \mathrm{C}$ 
TABLE IV(b) . MECHANICAL AND PHYSICAL PROPERTIES OF CARBON/KAPTON FIIMS

\begin{tabular}{|c|c|c|c|c|c|c|c|c|c|c|}
\hline $\begin{array}{l}\text { Specimen } \\
\text { Identification }\end{array}$ & $\begin{array}{l}114- \\
10-2\end{array}$ & $\begin{array}{c}105- \\
27\end{array}$ & $\begin{array}{l}114- \\
28-1\end{array}$ & $\begin{array}{c}113- \\
31\end{array}$ & $\begin{array}{l}114- \\
25-2\end{array}$ & $\begin{array}{c}114- \\
23\end{array}$ & $\begin{array}{c}114- \\
60\end{array}$ & $\begin{array}{l}114- \\
48-1\end{array}$ & $\begin{array}{l}114- \\
48-2\end{array}$ & $\begin{array}{l}113- \\
44-1\end{array}$ \\
\hline $\begin{array}{l}\text { Thickness ( } 10^{-3} \text { in.) } \\
\text { Specimen, total } \\
\text { Kapton substrate } \\
\text { Carbon coating, } \\
\text { total } \\
\text { Modulus of elas- } \\
\text { ticity ( } 10^{6} \text { psi) } \\
\text { Composite } \\
\text { Kapton substrate } \\
\text { Carbon coating } \\
\text { Ultimate elongation } \\
\text { of carbon } \\
\text { coating (\%) } \\
\text { Stress of coating } \\
\text { failure (ksi) } \\
\text { Composite } \\
\text { Carbon coating } \\
\text { Coefficient of } \\
\text { thermal expansion } \\
\left.\text { (lo-6 }{ }^{\circ} \mathrm{C}^{-1}\right) \\
\text { Composite } \\
\text { Kapton substrate } \\
\text { Carbon coating }\end{array}$ & $\begin{array}{l}1.96 \\
0.46 \\
24.6\end{array}$ & $\begin{array}{l}0.547 \\
0.512 \\
0.035\end{array}$ & $\begin{array}{l}0.561 \\
0.512 \\
0.049\end{array}$ & $\begin{array}{l}2.19 \\
0.50 \\
9.34\end{array}$ & $\begin{array}{l}0.654 \\
0.51 .2 \\
0.142\end{array}$ & $\begin{array}{l}0.679 \\
0.512 \\
0.167\end{array}$ & $\begin{array}{l}0.731 \\
0.538 \\
0.193\end{array}$ & $\begin{array}{l}4.57 \\
0.46 \\
14.5\end{array}$ & $\begin{array}{l}0.773 \\
0.538 \\
0.235\end{array}$ & $\begin{array}{l}9.47 \\
0.50 \\
17.6\end{array}$ \\
\hline
\end{tabular}


TABLE $V$. MECHANICAL AND PHYSICAL PROPERTIES OF VARIOUS COATINGS ON KAPTON FILM

\begin{tabular}{|c|c|c|c|c|c|c|}
\hline $\begin{array}{l}\text { Specimen Identification } \\
\text { Coating Material }\end{array}$ & $\begin{array}{l}113-35-1 \\
\text { Boron }\end{array}$ & $\begin{array}{l}113-35-2 \\
\text { Boron }\end{array}$ & $\begin{array}{l}114-52 \\
\text { Zircon }\end{array}$ & $\begin{array}{l}114-74 \\
\mathrm{Al}_{2} \mathrm{O}_{3}\end{array}$ & $\begin{array}{l}105-16-1 \\
\mathrm{Ti} / \mathrm{C}\end{array}$ & $\begin{array}{c}105-16-2 \\
\mathrm{Ti} / \mathrm{C}\end{array}$ \\
\hline $\begin{array}{l}\text { Thickness ( } 10^{-3} \text { in.) } \\
\text { Specimen, total } \\
\text { Kapton Substrate } \\
\text { Coating, total } \\
\text { Modulus of elasticity }\left(10^{6} \text { psi) }\right. \\
\text { Composite } \\
\text { Kapton substrate } \\
\text { Coating } \\
\text { U1timate elongation of coating (\%) } \\
\text { Stress of coating failure (ksi) } \\
\text { Composite } \\
\text { Coating } \\
\text { Coefficient of thermal expansion } \\
\left.\text { (10-6 }{ }^{\circ}{ }^{-1}\right) \\
\text { Composite } \\
\text { Kapton substrate } \\
\text { Coating }\end{array}$ & $\begin{array}{l}0.766 \\
0.536 \\
0.230\end{array}$ & $\begin{array}{l}3.91 \\
0.49 \\
14.0 \\
0.35 \\
13.6 \\
41.8\end{array}$ & $\begin{array}{l}1.83 \\
0.49 \\
6.75 \\
0.38 \\
\\
6.1 \\
17.6 \\
\\
6.4 \\
19.2 \\
3.0\end{array}$ & $\begin{array}{l}14.9 \\
46.9 \\
\\
-5.3 \\
19.2 \\
-7.1\end{array}$ & $\begin{array}{l}1.85 \\
0.49 \\
28.6 \\
0.584\end{array}$ & $\begin{array}{l}1.90 \\
0.49 \\
24.6 \\
0.548\end{array}$ \\
\hline
\end{tabular}




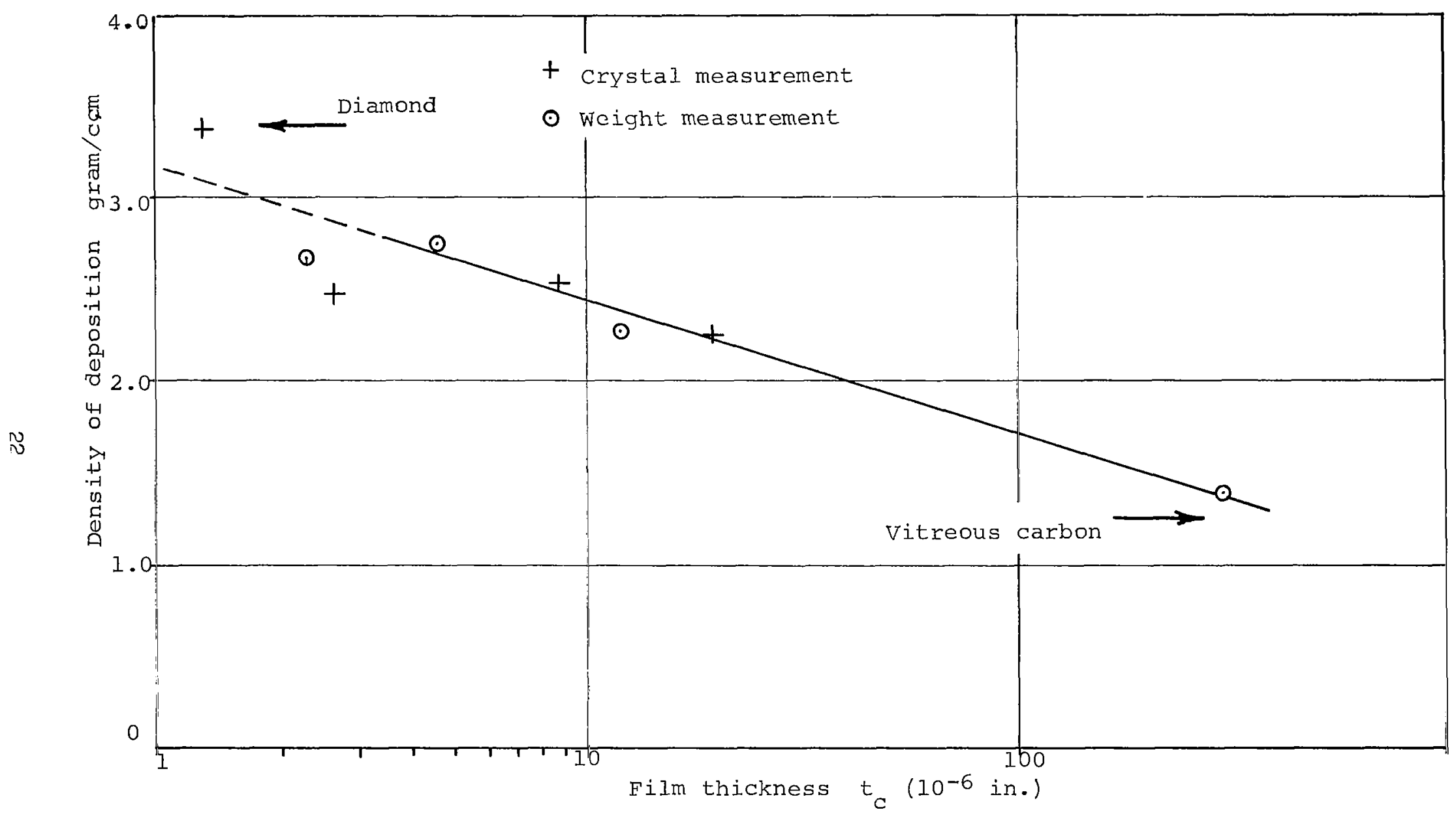

Figure 1. Density of Carbon Films as a Function of Deposition Thickness 


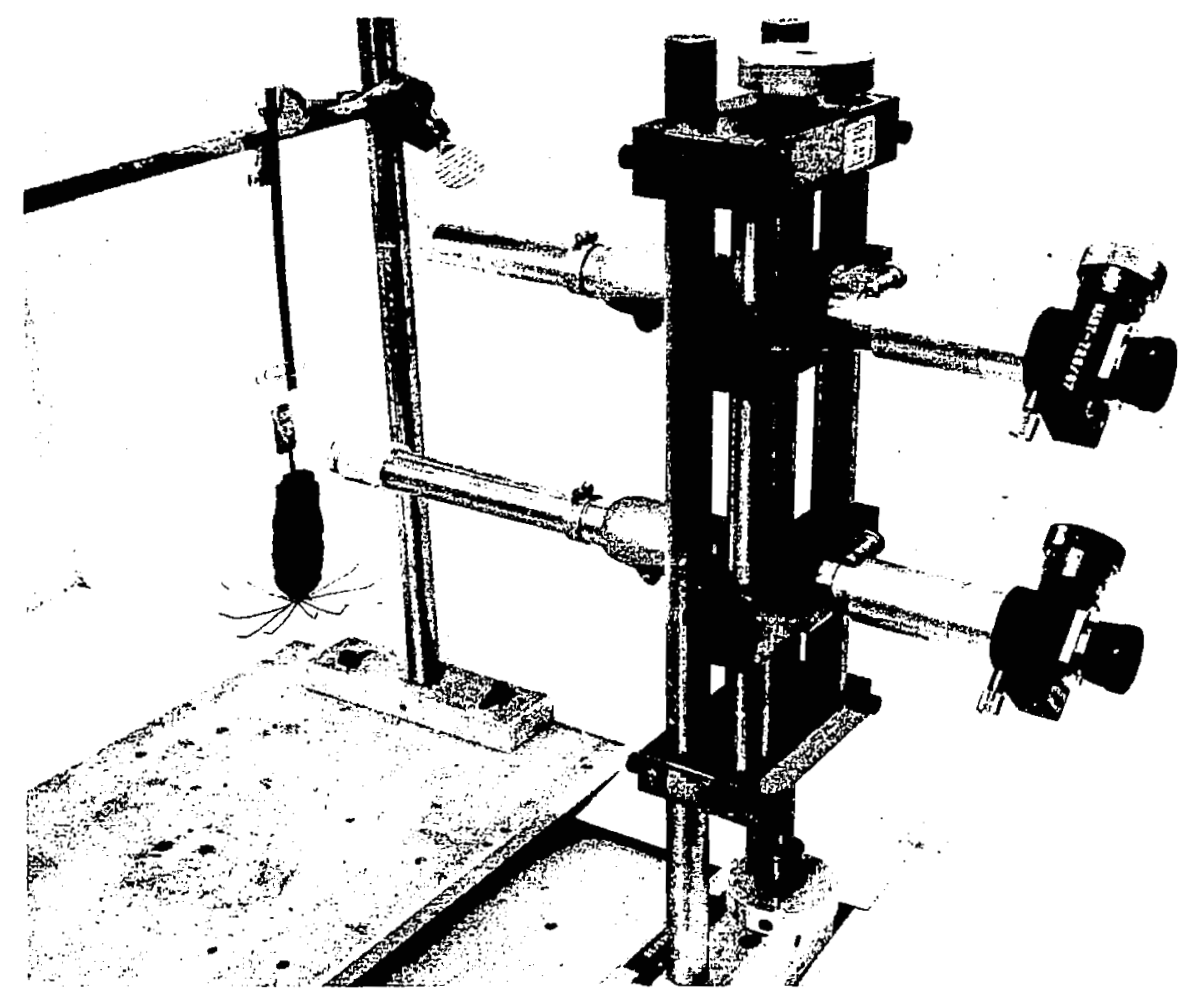

Figure 2. Twin Microscope Stand for Elongation Measurements 


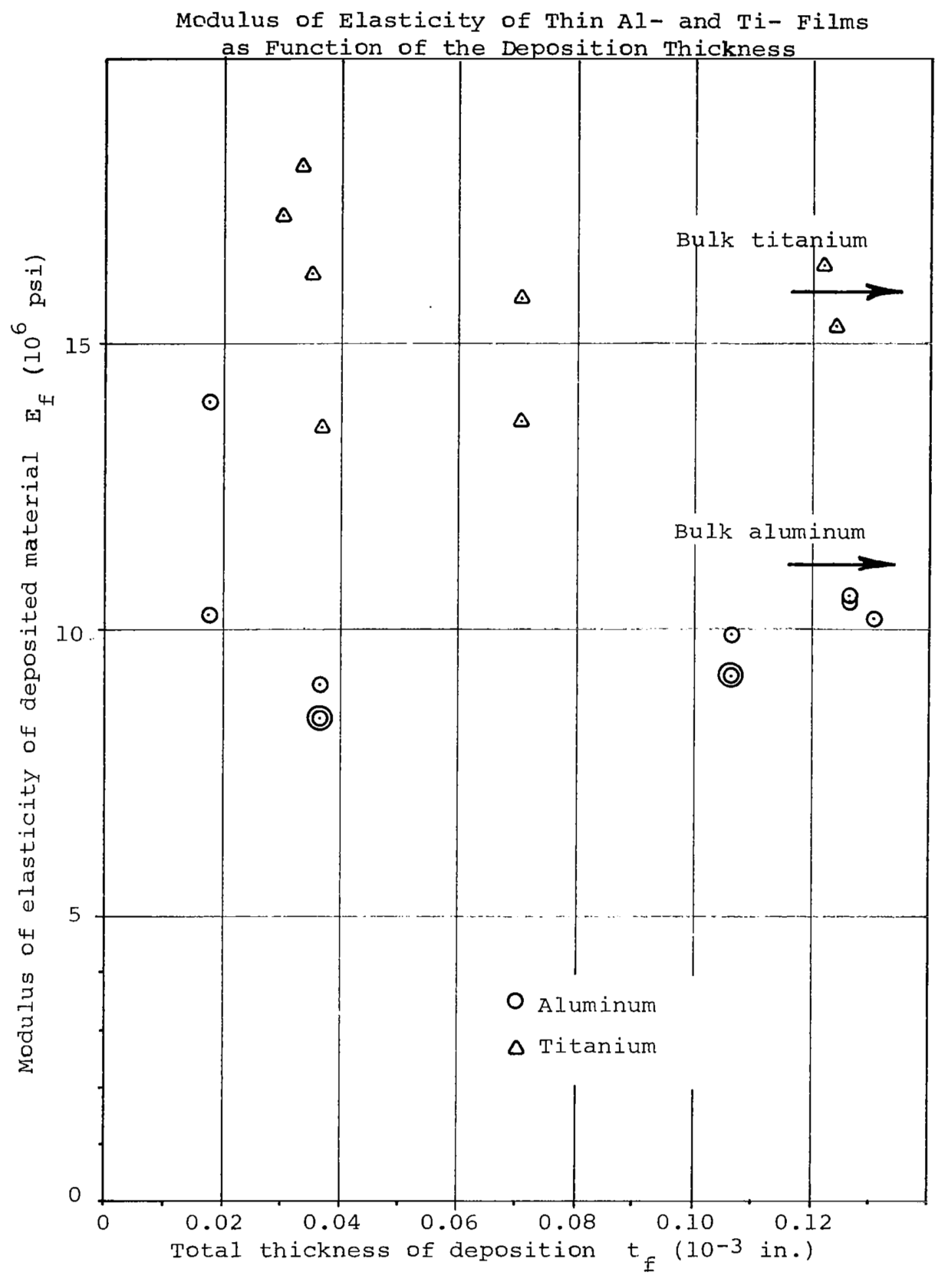

Figure 3. Elastic Modulus of Metal Films 


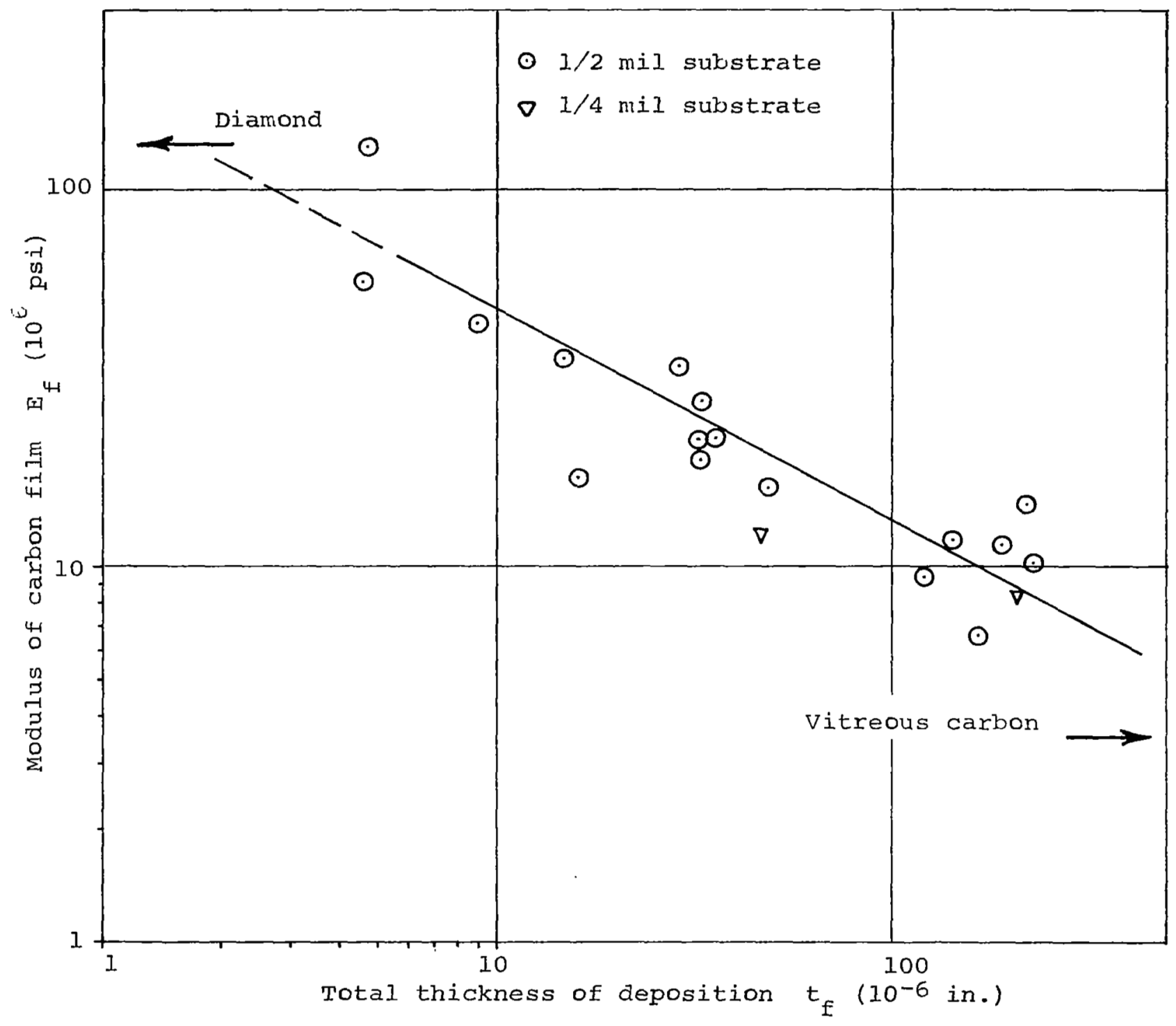

Figure 4. Elastic Modulus of Carbon Films 


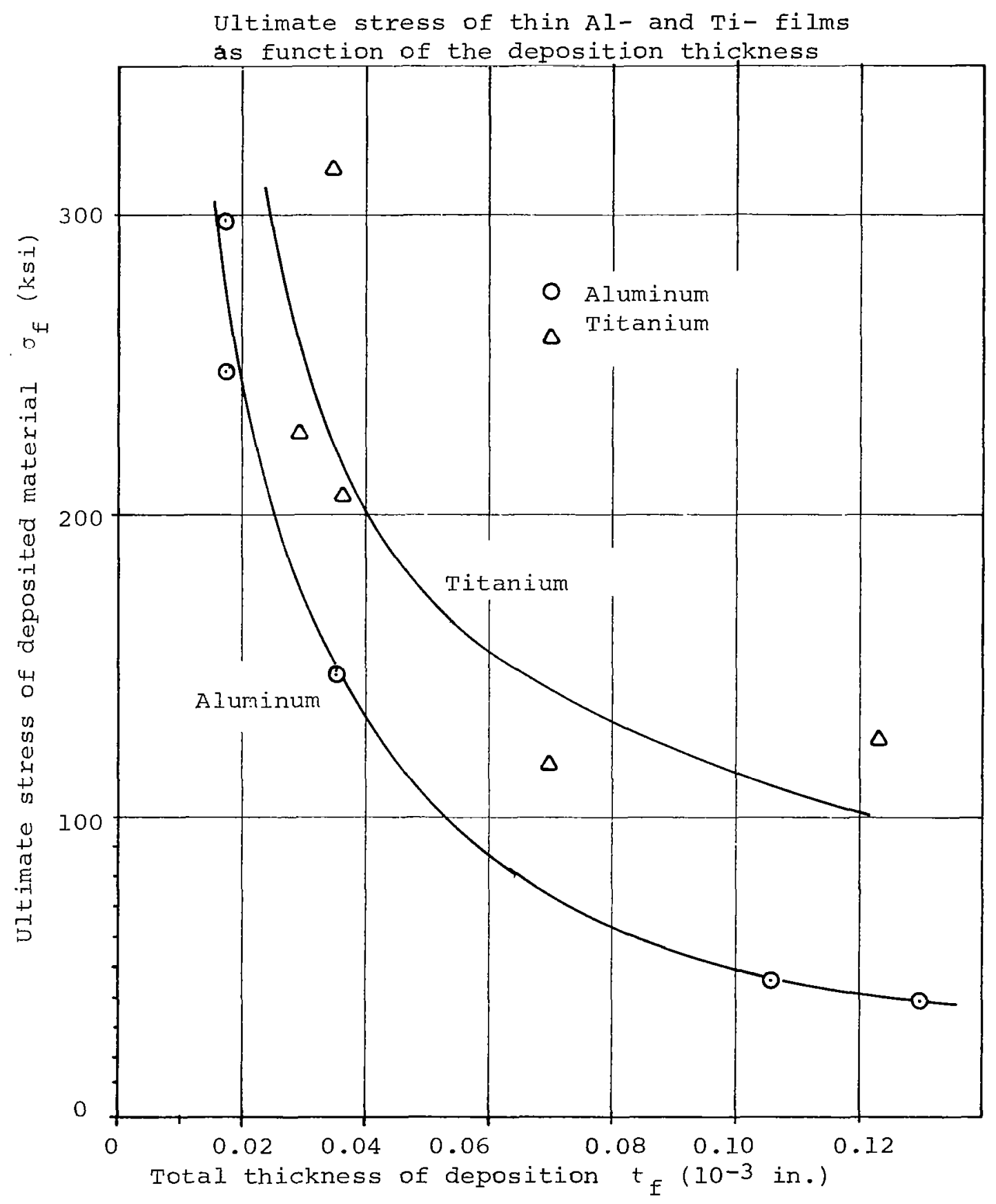

Figure 5. Tensile strength of Aluminum and Titanium Films 


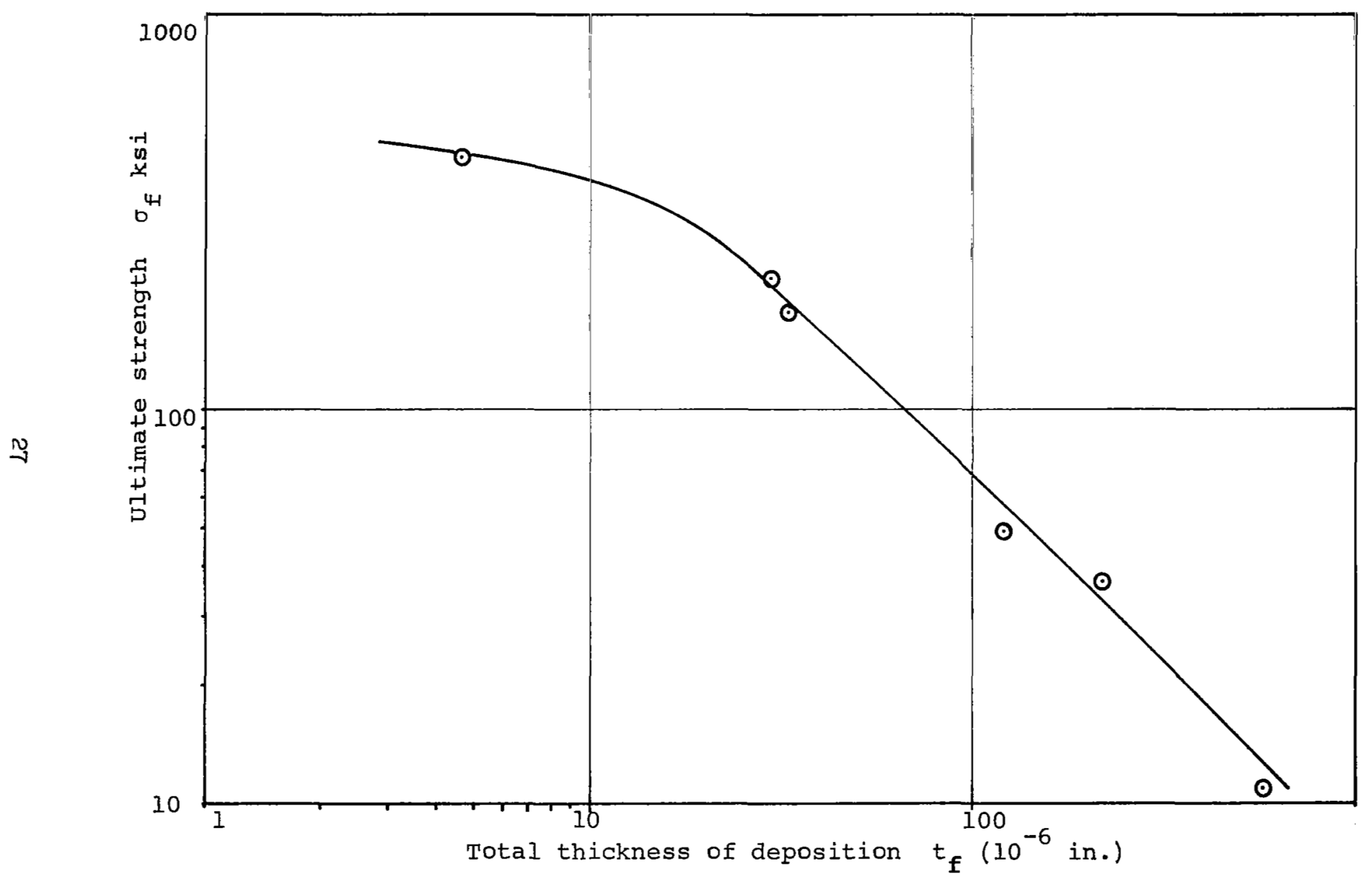

Figure 6. Tensile strength of Carbon Films 


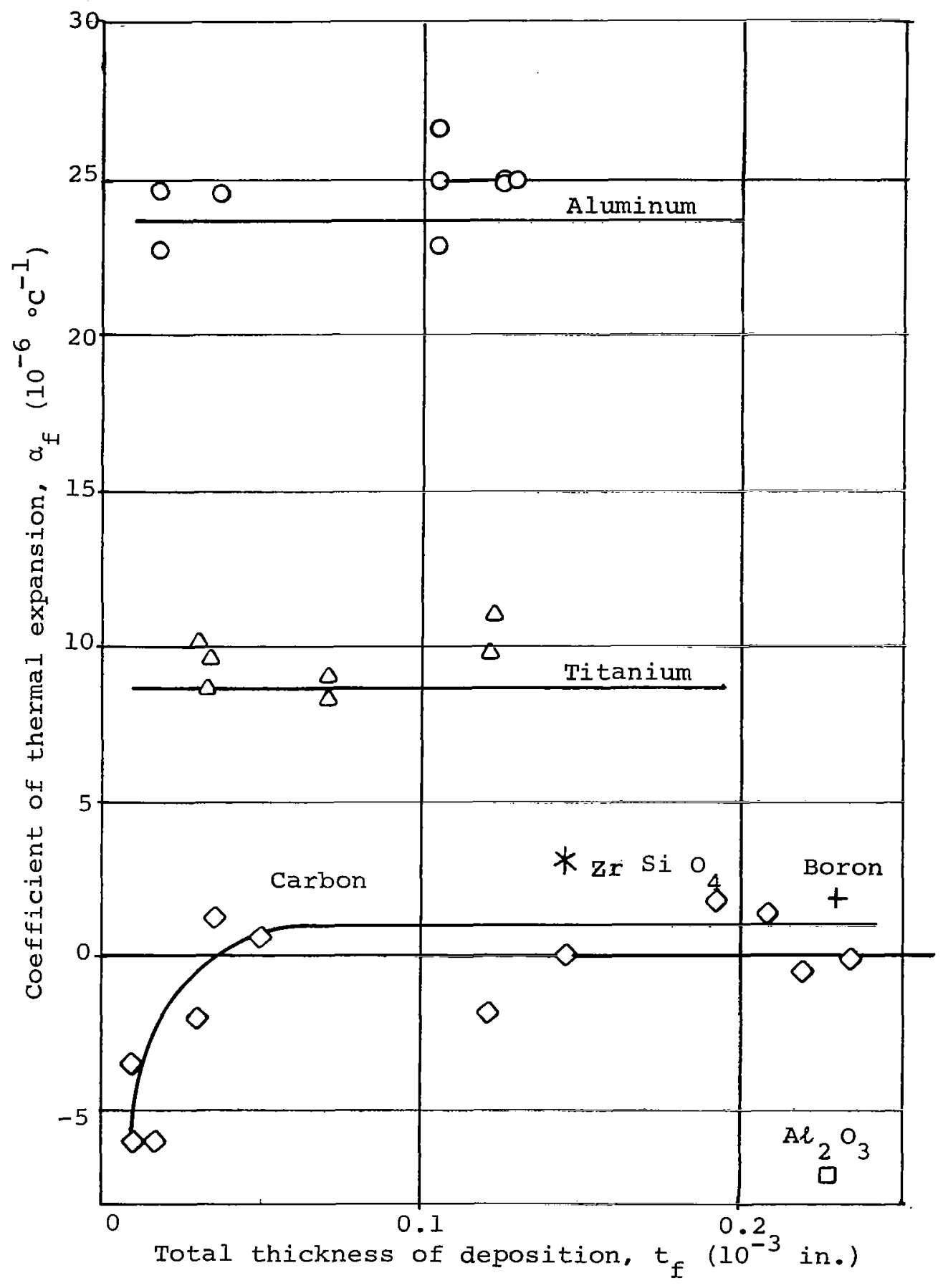

Figure 7. Thermal Expansion of Deposited Films. 